\title{
Chapter 10 \\ Non-income Dimensions, Prevalence, Depth and Severity of Poverty: Spatial Estimation with Household-Level Data in India
}

\section{Panchanan Das}

\begin{abstract}
This chapter examines the incidence, depth and severity of poverty and the effects of the major non-income dimensions on poverty in India after more than a decade of the initiation of the process of integration by using an independently pooled cross section from the 61st and 66th round household-level unit data provided by the National Sample Survey Office (NSSO). Poverty estimates are based on relative poverty lines at 75 and $50 \%$ of the median value of the distribution of per capita expenditure of the respective population groups. The chapter focuses on education, type of employment, land rights, social and religious factors, and gender-related issues among the non-income dimensions of poverty. The rising poverty incidence on the basis of relative poverty line in urban areas, as evidenced in this study, supports the hypothesis that urban inequality increased significantly during the post-reforms period in India. Per capita consumption expenditure on monthly basis in logarithmic terms is used in this study as a proxy for well-being or poverty. The study observes that land as a productive asset had very little positive effect on poverty. But the effect of education on the level of well-being was positive and increased with the level of education in every state in India. Technical education, a component of workers' skill, improved consumption per capita in all states except Chhattisgarh and Kerala. Scheduled Tribes and Scheduled Castes among the social groups and Muslims among religious groups are mostly deprived in terms of consumption per capita.
\end{abstract}

Keywords Poverty analysis • Distribution • Non-income dimension • India

JEL Classification I32 $\cdot \mathrm{O} 15 \cdot \mathrm{O} 53$

P. Das $(\bowtie)$

Department of Economics, University of Calcutta, Calcutta, India

e-mail: p.das.wbes@gmail.com 


\subsection{Introduction}

Absolute poverty has reduced during the phase of growth success that followed economic liberalisation in many Asian countries, notably in the People's Republic of China and India. However, there is growing evidence that inequality has been rising through the integration process in many parts of Asia (Chen and Ravallion 2004). In India, openness contributes to higher growth with more inequality not only between regions but also within a region, and the poor benefit disproportionately less from high growth (Das 2010). This widespread rise in inequality has been detrimental to the objective of poverty reduction.

While the process of integration of many Asian economies into the global economy has generated a significant growth impact on poverty, the poor in those countries are much more vulnerable to large shocks emanating from this process of integration. A detailed country-specific analysis is required to enhance our understanding of the depth of poverty during the process of deeper integration into the global economy by taking into account different counteracting forces and threshold effects. While the definition of international poverty line with countrywise purchasing power parity (PPP) adjustments seems to have little acceptance, figures generated by official estimates leave no room for doubt that India is the largest dwelling place for the income-poor in the world. The level of living as reflected in purchasing power of an average Indian was roughly one-third of the world average and one-tenth of the developed high-income countries in 2004 (Radhakrishna and Panda 2006).

The reliability of official estimates has, however, been the focal point of the debate that raged over the question of whether the post-reforms growth in India has been pro-poor. The main contestants in the debate focused entirely on the income dimension of poverty, ignoring non-income criteria such as health, education and employment. Obviously, they have bypassed the relevance and significance of linkages between income and non-income dimensions of poverty.

Against this backdrop, this chapter attempts to analyse the incidence, depth and severity of poverty, and the effects of the major non-income dimensions on poverty in India after more than a decade of the initiation of the process of integration, by using household-level unit data provided by the National Sample Survey Office (NSSO). The paper focuses mainly on education, type of employment, land rights, social and religious factors, and gender-related issues among the nonincome dimensions of poverty. In rural areas, age-old institutions like land relations raise the inequality effect of per capita GDP growth and perpetuate chronic poverty, especially among landless agricultural labourers and marginal farmers (Sanyal and Das 2008). The rural-urban migration of labourers contributes to urban poverty with higher inequality by preventing real wages to rise in the informal sector. In this paper, we hypothesise that while absolute poverty has declined, relative poverty or inequality has been increasing significantly, particularly in the urban economy, in India through the process of deregulation and openness of the economy since the early 1990s. 
Poverty is treated as an outcome of multidimensional factors that include not only income and calorie intake but also different social, economic and demographic factors. Access to land and credit, nutrition, health and longevity, literacy and education, safe drinking water, sanitation and other infrastructural facilities has a crucial impact on poverty at the household level as well as the country level. In this chapter, we examine the impacts of non-income dimensions-mostly related to the demographic and social characteristics of the households, and the highest level of education within the family — on poverty. Demographic and other characteristics of households have a direct and indirect impact on household income and consumption. Changes in household size, age and gender composition of household members influence the extent of poverty at the household level.

\subsection{Pooled Data and Construction of Variables}

We have constructed an independently pooled cross section ${ }^{1}$ from randomly selected households as recorded in the NSS 61st and 66th quinquennial rounds survey for 2004-2005 and 2009-2010, respectively. ${ }^{2}$ From statistical standpoint, this kind of data set consists of independently sampled observations. By pooling random samples drawn from the same population, but at different points in time, we can get more precise estimators and test statistics with more power (Wooldridge 2009). To capture the change in sampling distributions of a single random sample over time, we allow the intercept to differ over periods by introducing year dummy variables in the estimating model. The year dummy can be interpreted as the change in the effect of control variables on the dependent variable. We can also make a year dummy interact with key explanatory variables to see whether the effect of those variables has changed over a certain time period. We have taken the logarithmic values of per capita consumption expenditure on monthly basis (mpce), a proxy for the level of well-being, as the dependent variable, and household size and amount of land owned as the control variables.

Different dummy variables are used to represent different levels of education among the households. Technical education and vocational training with appropriate dummies are used as a proxy for skill. Type of employment has been distinguished between agricultural or land-based activities and non-farm activities among different types as recorded in the survey schedule. A gender dummy, 1 for

\footnotetext{
${ }^{1}$ If a random sample is drawn at different time periods, pooling of the random samples forms an independently pooled cross section.

2 The sample consists of 165,434 and 100,957 households in the 61st and 66th rounds respectively. The survey in each round of this type is based on stratified multi-stage sampling. The census villages in the rural sector and urban frame survey blocks in the urban sector are the firststage sample units. The final-stage ultimate sample units are households selected by simple random sample without replacement (SRSWOR) in both the sectors.
} 
women-headed households and 0 otherwise, and a sector dummy, 1 for rural and 0 for urban areas, have been constructed. Muslims, the religious minorities, are conventionally regarded as more deprived than Hindus and other religious communities. To capture the effect of relative deprivation of this religious group, we have incorporated a religion dummy, 1 for Muslims and 0 for others. It has been well established in the poverty literature on India that Scheduled Castes and Scheduled Tribes are the most deprived among different social groups as defined by the NSSO. To look at the extent of deprivation of these disadvantaged groups compared to other social groups, separate group dummies for Scheduled Tribes and Scheduled Castes have been constructed.

\subsection{Methodology}

(a) Estimating prevalence, depth and severity of relative poverty

The estimates of poverty in India are mainly based on the consumer expenditure surveys of the NSSO, and there has been a vast literature on poverty in India discussing different issues at both the conceptual and empirical levels. In most of the studies, estimates of poverty have been computed on the basis of the official poverty line at the all-India and state levels for the rural and urban sectors. The Tendulkar Committee recommended the use of implicit prices derived from quantity and value data collected in household consumer expenditure surveys for computing and updating the official poverty lines for the first time. The state-wise urban poverty lines of 2004-2005 are updated for 2009-2010, based on price rise during this period using Fisher's implicit price indices. The state-specific rural poverty lines are obtained from the urban poverty lines by adjusting the ruralurban price differential (GOI 2012). The recent debate on official poverty line suggested by the Planning Commission of India has mostly concentrated on the arbitrariness in fixing minimal requirements (Krishnaji 2012).

In this chapter, the incidence of poverty has been estimated by using the relative poverty line at different thresholds, namely 75 and $50 \%$ of the median mpce $^{3}$ of the distribution of per capita expenditure of the respective population groups. People whose incomes fall below this line are considered to be at the risk of poverty. Households with income below the relative poverty line are not necessarily poor by the conventional calorie norms, but they are in the lowerincome group compared with the population at large. The relative poverty focuses more on the disparities between the rich and the poor. The estimate of poverty at the lower threshold level provides a measure of chronic poverty with higher poverty risk. Thus, the poverty risk at $50 \%$ of the median expenditure

\footnotetext{
${ }^{3}$ A threshold fixed at a certain percentage of median expenditure is known as the relative poverty line.
} 
per capita as a threshold is higher than the risk at $75 \%$ of the median value of it. The chronically poor are at the margin of society and suffer from extreme deprivation.

This paper uses the most widely used poverty index of Foster, Greer and Thorbecke (1984), popularly known as FGT index, to find out the prevalence, depth and severity of poverty in India. The FGT index in one dimension $\left(y_{i}\right)$ is defined as

$$
\hat{P}(z, \alpha)=\frac{\sum_{i=1}^{n} w_{i}\left(z-y_{i}\right)_{+}^{\alpha}}{\sum_{i=1}^{n} w_{i}}
$$

where $z$ is the poverty line and $x_{+}=\max (x, 0)$

$$
w_{i}=h w_{i} * h s_{i}
$$

$h w_{i}$ is sampling weight for observation $\mathrm{i}$

$h s_{i}$ is size of observation $i$ (for example the size of household $i$ )

The usual normalised FGT index is estimated as

$$
\widehat{P}(z, \alpha)=\frac{\hat{P}(z, \alpha)}{z^{\alpha}}
$$

The parameter $\alpha$ is non-negative. When $\alpha=0$, the FGT index gives the simplest and most commonly used poverty headcount ratio. Although it is easy to interpret, the head count ratio is not sensitive to how far below the poverty line poor people are. For $\alpha=1$, it measures the average poverty gap, showing the shortfall of the poor's expenditure from the poverty line, expressed as an average of all people in the population. It can be used as an indicator of the minimum cost of eliminating poverty through targeted transfers. When $\alpha$ is set equal to 2, the FGT is the poverty severity index which is sensitive to the distribution of living standards among the poor. It takes into account the variations in distribution of welfare among the poor. An increase in poverty gap increases the FGT index, and an equalising Pigou-Dalton transfer would often decrease the poverty index. When $\alpha$ is larger, the index puts more weight on the position of the poorest. These three poverty measures have the useful property of being additively decomposable.

(b) Estimating the contributions of non-income parameters to poverty

A simple way to look at the relationship between the level of well-being and its major non-income parameters is to estimate a linear multiple regression model. The logarithmic value of mpce is taken as a proxy for well-being. Higher the value of mpce, lower will be the probability of a household being poor. The regression equation in the frame of pooled data from two independent random samples is specified as 


$$
\begin{aligned}
\ln y= & \alpha_{0}+\alpha_{1} x_{1}+\alpha_{2} x_{2}+\alpha_{3} D^{y 09}+\sum_{i=1}^{4} \beta_{i} D_{i}^{t e c h}+\gamma_{1} D^{\text {tech }}+\gamma_{2} D^{t r} \\
& +\theta_{1} D^{r}+\theta_{2} D^{m}+\theta_{3} D^{s t}+\theta_{4} D^{s c}+\theta_{5} D^{f}+\theta_{6} D^{a g r i}+\eta_{1} D^{r} D^{y 09}+\eta_{2} D^{m} D^{y 09} \\
& +\eta_{3} D^{s t} D^{y 09}+\eta_{4} D^{s c} D^{y 09}+\eta_{5} D^{f} D^{y 09}+\eta_{6} D^{a g r i} D^{y 09} \\
& +\sum_{i=1}^{4} \delta_{i} D_{i}^{e d u} D^{y 09}+\lambda_{1} D^{t e c h} D^{y 09}+\lambda_{2} D^{t r} D^{y 09}+\varepsilon
\end{aligned}
$$

Here, log of mpce $(y)$ is taken as a dependant variable measuring approximately the level of well-being of the household. Household size $\left(x_{1}\right)$ and land owned $\left(x_{2}\right)$ are the quantitative variables used as regressors. The inter-temporal effect of different non-income dimensions are measured by the year dummy $D^{\mathrm{y} 09}$, equal to 1 if the sample household comes from the 66th round (2009-2010) and 0 if it comes from the 61st round (2004-2005). Education, perhaps, is the most important factor affecting poverty. We have incorporated four dummy variables $D_{i}^{e d u}, \mathrm{i}=1$ to 4 representing 4 levels of education, namely primary, middle school, graduate and postgraduate. To look into the contribution of skill, two more dummy variables relating to skill, $D^{\text {tech }}$ for households with technical education and $D^{t r}$ for households with vocational training have been considered in our econometric model specified in Eq. (10.3). The variable $D^{r}$ is a dummy variable with its value equal to 1 if the household lives in a rural area and 0 for otherwise.

Social factors are important in determining the capacity of the household to maintain minimum standard of living. The minority community, particularly Muslims, in India have been more deprived compared to Hindus and other communities for historical reasons. Similarly, Scheduled Tribes and Scheduled Castes are relatively more backward than other social groups in the country. The levels of poverty among these backward communities have been differentiated by using appropriate dummy variables. We define $D^{m}$ as a religion dummy with its value equal to 1 representing Muslims and 0 for all other religions; the social group dummy $D^{s t}$ captures Scheduled Tribes, and $D^{s c}$ captures Scheduled Castes. Gender is an important issue in analysing the economic condition of the vulnerable sections of society. The relative position of the female-headed household is looked at by incorporating gender dummy. The variable $D^{f}$ is a gender dummy variable equal to 1 for women-headed households and 0 for men-headed households. A household's occupation is also an important determinant affecting the level of poverty. In our empirical exercise, we have distinguished between two different types of employment by introducing a dummy variable $D^{a g r i}$ that equals unity for agricultural households and zero for others. $\varepsilon$ is an i.i.d. idiosyncratic error term with mean zero and constant variance $\sigma_{\varepsilon}^{2}$, measuring the effects of unobservable factors.

The intercept term $\left(\alpha_{0}\right)$ measures the effect of the factors on well-being not included in the model. The intercept, for example, is $\alpha_{0}$ for urban households in 2004-2005 and $\left(\alpha_{0}+\theta_{1}\right)$ for rural households. The intercept for urban households is $\left(\alpha_{0}+\alpha_{3}\right)$ in 2009-2010 and $\left(\alpha_{0}+\theta_{1}+\alpha_{3}\right)$ for rural households. 
We can interpret the other coefficients in a similar manner. To estimate the differential effects of the household-specific factors on poverty level in two different time periods, we have used interacted dummy variables. The year dummy can be interpreted as the change in the effect of control variables on the dependent variable due to a change in the time period. We have interacted year dummy with key explanatory variables to see whether the effect of those variables has changed over the period 2004-2005 to 2009-2010. The coefficients $\beta$ is act as the effects of schooling at different levels in 2004-2005, and the inter-temporal change in the effects of education on poverty during the period 2004-2005 to 2009-2010 will be $\left(\beta_{i}+\delta_{i}\right)$

\subsection{Empirical Results}

The 66th round (2009-2010) survey on household consumer expenditure brings to light the prevalence of the deep urban-rural divide in terms of consumption spending. Per capita spending of urban India was almost double that of rural India. ${ }^{4}$ The consumption inequality was high within both the rural and urban populations, but higher within the urban population. The top $10 \%$ of India's rural population having an average mpce of Rs. 2,517 was 5.6 times that of the poorest $10 \%$ (Rs. 453). In urban areas, on the other hand, average mpce (Rs. 5,863) of the top $10 \%$ was 9.8 times higher than average mpce (Rs. 599) of the bottom $10 \%$. This disparity is further accentuated by the significant inequalities between states, as evidenced by the survey. The rural average mpce in Kerala, for example, was Rs. 1,835, while that in Bihar was only Rs. 780. One of the major factors contributing to widening regional disparities is the variation in performance of the government's social safety net programs after reforms.

(a) Measuring FGT index

By utilising household-level information on monthly consumption expenditure per capita from schedule 10 of the 61st and 66th round quinquennial surveys for the period 2004-2005 and 2009-2010, the FGT index at $\alpha=0,1$ and 2 has been estimated separately for rural and urban locations in India by taking poverty lines at 75 and $50 \%$ median expenditure of the respective population groups. The poverty line at $50 \%$ of the median of the expenditure distribution is used in estimating chronic poverty. The estimates are shown in Table 10.1. The incidence of relative poverty was higher in urban locations than in the countryside, and the rural-urban gap increased in terms of prevalence, depth and severity of poverty in India during the period 2004-2009. While the estimate of poverty risk remained at the same level, or even declined in the rural economy, the poverty incidence increased in urban centres at both thresholds and at different values of $\alpha$ during this period.

\footnotetext{
${ }^{4}$ In 2009-2010, the average mpce was Rs. 1,054 and 1,984 in rural and urban India respectively.
} 
Table 10.1 FGT index of prevalence, depth and severity of poverty in India: 2004-2009

\begin{tabular}{l|l|l|l|l|l}
\hline \multirow{2}{*}{} & \multirow{3}{*}{ Year } & \multicolumn{2}{|l|}{$\begin{array}{l}75 \% \text { median } \\
\text { mpce }\end{array}$} & \multicolumn{2}{l}{$\begin{array}{l}50 \% \text { median } \\
\text { mpce }\end{array}$} \\
\cline { 3 - 6 } & & Rural & Urban & Rural & Urban \\
\hline$\alpha=0$ & $2004-2005$ & 0.23 & 0.29 & 0.03 & 0.08 \\
\cline { 2 - 6 } & $2009-2010$ & 0.25 & 0.32 & 0.05 & 0.11 \\
\hline \multirow{2}{*}{$\alpha=1$} & $2004-2005$ & 0.04 & 0.07 & 0.005 & 0.013 \\
\cline { 2 - 6 } & $2009-2010$ & 0.05 & 0.09 & 0.01 & 0.02 \\
\hline$\alpha=2$ & $2004-2005$ & 0.01 & 0.02 & 0.002 & 0.004 \\
\cline { 2 - 6 } & $2009-2010$ & 0.02 & 0.03 & 0.002 & 0.006 \\
\hline
\end{tabular}

Source Author's estimation based on 61st and 66th round NSS unit-level data

In official estimates, the incidence of rural poverty was higher than urban poverty in 2009-2010, and the poverty incidence declined in both rural and urban areas, although at a slower rate in urban India than in the countryside. ${ }^{5}$ The head count measure as obtained in this study, although apparently contrasting with the official estimates, may not be surprising because our estimates are based on the distributional characteristics of monthly expenditure per capita. While the official estimates provide information about absolute poverty, our estimates highlight the relative poverty or risk of poverty. In this study, the higher incidence of poverty in urban locations implies higher poverty risk with higher inequality as compared to the countryside. The rising poverty incidence, as displayed in Table 10.1, on the basis of relative poverty line in urban areas supports the hypothesis that urban inequality increased significantly during the post-reforms period in India.

If we fix poverty line at $75 \%$ of the median expenditure per capita of the population groups, one-fourth of the rural population and roughly one-third of the urban population still remained below the poverty line during 2009-2010. The incidence of chronic poverty at $50 \%$ of the median expenditure as threshold was 5 and $11 \%$, respectively, in rural and urban areas during the same period. In order to look at the shortfall of the poor's expenditure from the poverty line, we have estimated the poverty gap index (FGT at $\alpha=1$ ) measuring the intensity or depth of poverty. According to this estimate, the depth of poverty in the countryside was 5 and $1 \%$, respectively, in 2009-2010 at the two poverty thresholds used in this study. The respective figures in the urban economy were 9 and $2 \%$ at that time, revealing that the depth of poverty, even chronic poverty, was significantly higher at any threshold in the urban areas than in rural areas. The severity of poverty measured by FGT at $\alpha=2$ was at 1 and $3 \%$ in the rural and urban economy, respectively, while the index was negligible among the chronically poor in both rural and urban sectors in 2009-2010. Although we are not looking at

\footnotetext{
5 According to the official estimates based on the Tendulkar methodology, the poverty ratio declined from 41.8 to $33.8 \%$ in rural areas and from 25.7 to $20.9 \%$ in urban areas during 2004-2009.
} 
Table 10.2 Estimated poverty risk at different threshold by states in 2009-2010

\begin{tabular}{|c|c|c|c|c|}
\hline \multirow{2}{*}{$\begin{array}{l}\text { Threshold level } \\
\text { states }\end{array}$} & \multicolumn{2}{|l|}{ Rural } & \multicolumn{2}{|l|}{ Urban } \\
\hline & $\begin{array}{l}75 \% \text { median } \\
\text { mpce }\end{array}$ & $\begin{array}{l}50 \% \text { median } \\
\text { mpce }\end{array}$ & $\begin{array}{l}75 \% \text { median } \\
\text { mpce }\end{array}$ & $\begin{array}{l}50 \% \text { median } \\
\text { mpce }\end{array}$ \\
\hline Andhra Pradesh & 0.14 & 0.02 & 0.26 & 0.08 \\
\hline Assam & 0.23 & 0.02 & 0.41 & 0.18 \\
\hline Bihar & 0.44 & 0.09 & 0.60 & 0.34 \\
\hline Chhattisgarh & 0.46 & 0.13 & 0.41 & 0.20 \\
\hline Gujarat & 0.17 & 0.02 & 0.29 & 0.10 \\
\hline Haryana & 0.07 & 0.01 & 0.23 & 0.07 \\
\hline $\begin{array}{l}\text { Himachal } \\
\text { Pradesh }\end{array}$ & 0.04 & 0.001 & 0.20 & 0.03 \\
\hline Jharkhand & 0.50 & 0.07 & 0.45 & 0.23 \\
\hline Karnataka & 0.24 & 0.03 & 0.33 & 0.14 \\
\hline Kerala & 0.04 & 0.001 & 0.24 & 0.09 \\
\hline Madhya Pradesh & 0.44 & 0.15 & 0.46 & 0.22 \\
\hline Maharashtra & 0.13 & 0.01 & 0.24 & 0.08 \\
\hline Odisha & 0.47 & 0.16 & 0.47 & 0.26 \\
\hline Punjab & 0.04 & 0.001 & 0.24 & 0.06 \\
\hline Rajasthan & 0.13 & 0.01 & 0.30 & 0.10 \\
\hline Tamil Nadu & 0.15 & 0.02 & 0.32 & 0.13 \\
\hline Uttar Pradesh & 0.34 & 0.05 & 0.53 & 0.26 \\
\hline Uttaranchal & 0.06 & 0.001 & 0.30 & 0.09 \\
\hline West Bengal & 0.24 & 0.04 & 0.33 & 0.13 \\
\hline
\end{tabular}

Source Author's estimation based on 66th round NSS unit-level data

inter-group differences in poverty incidence in detail in this paper, it may be quite natural that the higher poverty incidence in the urban locations has further been disproportionately high among historically marginalised groups such as Scheduled Castes, Scheduled Tribes, the elderly, women and the disabled. This is because people belonging to the Scheduled Castes and Other Backward Classes, and the Scheduled Tribes in particular, are lagging far behind the general category population in terms of the depth of poverty (Das 2012).

The rural-urban gap in relative deprivation varied widely across the major states in India. The estimates of poverty risk in terms of FGT poverty index at $\alpha=0$ representing the poverty headcount ratio for different states during 2009-2010 are shown in Table 10.2. The incidence of poverty was significantly higher in urban areas than in rural areas at both threshold levels of consumption everywhere in India. But the prevalence of poverty was not distributed uniformly across the states in India, both in rural and urban locations, at any threshold level for obvious reasons. In the rural economy, the prevalence of relative poverty was the highest in Jharkhand, followed by Odisha, Chhattisgarh, Bihar and Madhya Pradesh in 2009-2010. These states are traditionally lagging behind in terms of any 
parameter of growth, displaying a higher incidence of poverty. The distributionsensitive rural poverty was lower in Punjab, Kerala, and Uttaranchal at that time. The chronic poverty in the countryside was severe in Odisha, Madhya Pradesh and Chhattisgarh during this period. In urban locations, the poverty risk was significantly higher in Bihar, Uttar Pradesh, Madhya Pradesh and Jharkhand among the major states of the country in 2009-2010. The extent of poverty risk at $75 \%$ of median expenditure was lower than the national average in Himachal Pradesh, Haryana, Punjab, Maharashtra and Kerala. The prevalence of urban poverty in a chronic sense was the most severe in Bihar, followed by Uttar Pradesh, Odisha and Jharkhand. The chronic poverty among the people living in urban areas was lower in Himachal Pradesh, Punjab and Haryana.

(b) OLS estimates of contributions of non-income parameters

Per capita consumption expenditure on monthly basis in logarithmic terms is used in this study as a proxy for well-being or poverty. The higher the value of expenditure per capita, the lower will be the probability of a household being poor. In finding out the inter-temporal effect of non-income dimensions of poverty on the level of well-being, we used household-level pooled data from a random sample of households as recorded in NSS 61st and 66th rounds survey for the period 2004-2005 and 2009-2010, respectively. Total sample observations of 165,434 and 100,957 households have been used from these two rounds to form the pooled data set covering all most all regions in India.

The OLS estimation of the coefficients of the relationship as specified in Eq. (10.3) is shown in Table 10.3. The Breusch-Pagan test suggests that there is no heteroscedasticity problem in the model. ${ }^{6}$ The lower panel of Table 10.3 provides some statistics on goodness of fit. Most of the estimated coefficients are significant at less than $1 \%$ level. The intercept term is positive, implying that all the other observable factors not included in the model had a positive effect on wellbeing. Household size had a significant negative effect on well-being of the household as measured by consumption per capita in logarithmic terms. The higher the household size, the lower will be the per capita expenditure only when total expenditure or income increases at a lower proportional rate than the rise in family size. It may be a gross indication of lower job opportunities even in the informal sector. Land as a productive asset had very little positive effect on well-being. In Table 10.3, the coefficient of land owned is zero even at two decimal points. Thus, non-farm activities are more significant than land-based activities in reducing household poverty in India, even during the post-liberalisation era. The positive coefficient of the time dummy variable reveals that the effects of non-income parameters on poverty improved in 2009 as compared to the effects in 2004.

\footnotetext{
6 The Breusch-Pagan (1979) test is designed to detect any linear form of heteroscedasticity. It tests the null hypothesis that the error variances are all equal versus the alternative that the error variances are a multiplicative function of one or more variables.
} 
Table 10.3 Estimated coefficients of non-income dimensions of poverty in India

\begin{tabular}{|c|c|c|c|}
\hline Variables & Estimated coefficient & $t$-statistic & $P>t$ \\
\hline Intercept & 6.745 & $1,615.88$ & 0.000 \\
\hline Household size & -0.062 & -148.58 & 0.000 \\
\hline Land owned & 0.000 & 19.44 & 0.000 \\
\hline $\mathrm{D}^{\text {agr }}$ & -0.002 & -0.53 & 0.594 \\
\hline$D^{f}$ & 0.079 & 19.13 & 0.000 \\
\hline $\mathrm{D}^{\text {edu_primary }}$ & 0.155 & 46.82 & 0.000 \\
\hline $\mathrm{D}^{\text {edu_middle }}$ & 0.362 & 111.3 & 0.000 \\
\hline $\mathrm{D}^{\text {edu_graduate }}$ & 0.714 & 120.98 & 0.000 \\
\hline D $^{\text {edu_pg }}$ & 0.885 & 87.24 & 0.000 \\
\hline$D^{\text {edu_tech }}$ & 0.131 & 17.26 & 0.000 \\
\hline $\mathrm{D}^{\text {training }}$ & 0.019 & 3.06 & 0.002 \\
\hline $\mathrm{D}^{\text {muslim }}$ & -0.044 & -11.01 & 0.000 \\
\hline $\mathrm{D}^{\mathrm{st}}$ & -0.010 & -2.68 & 0.007 \\
\hline $\mathrm{D}^{\mathrm{sc}}$ & -0.174 & -49.35 & 0.000 \\
\hline $\mathrm{D}^{\text {year }}$ & 0.464 & 78.77 & 0.000 \\
\hline $\mathrm{D}^{\text {rural }}$ & -0.225 & -69.46 & 0.000 \\
\hline $\mathrm{D}^{\text {agr } * \mathrm{D}^{\text {year }}}$ & 0.024 & 4.65 & 0.000 \\
\hline $\mathrm{D}^{\mathrm{f} * \mathrm{D}^{\text {year }}}$ & 0.026 & 3.86 & 0.000 \\
\hline$D^{\text {edu_primary }} * D^{\text {year }}$ & -0.020 & -3.45 & 0.001 \\
\hline $\mathrm{D}^{\text {edu_middle } *} \mathrm{D}^{\text {year }}$ & -0.007 & -1.27 & 0.206 \\
\hline $\mathrm{D}^{\text {edu_graduate } *} \mathrm{D}^{\text {year }}$ & -0.027 & -3.01 & 0.003 \\
\hline $\mathrm{D}^{\text {edu_pg}} * \mathrm{D}^{\text {year }}$ & -0.026 & -1.76 & 0.078 \\
\hline$D^{\text {edu_tech }} * D^{\text {year }}$ & 0.005 & 0.36 & 0.718 \\
\hline $\mathrm{D}^{\text {muslim*} * \mathrm{D}^{\text {year }}}$ & -0.035 & -5.38 & 0.000 \\
\hline $\mathrm{D}^{\mathrm{st} *} \mathrm{D}^{\text {year }}$ & -0.102 & -16.67 & 0.000 \\
\hline $\mathrm{D}^{\mathrm{sc} *} \mathrm{D}^{\text {year }}$ & 0.017 & 2.92 & 0.004 \\
\hline $\mathrm{D}^{\text {rural } * \mathrm{D}^{\text {year }}}$ & -0.002 & -0.36 & 0.718 \\
\hline \multicolumn{2}{|c|}{$F(26,232,678)=7,390.48$} & \multirow{2}{*}{\multicolumn{2}{|c|}{$\begin{array}{l}R^{2}=0.4523 \\
\text { Adj } R^{2}=0.4522\end{array}$}} \\
\hline Prob $>F=0.0000$ & & & \\
\hline
\end{tabular}

Source As for Table 10.1

The positive coefficient on the year dummy, $\mathrm{D}^{\mathrm{y} 09}$, also indicates an inflationary factor for nominal values of mpce in 2009-2010. ${ }^{7}$

We have taken the level of highest education among the family members within a household as one of the major non-income factors of poverty. The estimated results as displayed in Table 10.3 suggest that the households with educated members were better off than those without education. The poverty-reducing effect of

${ }^{7}$ Let $\mathrm{P}^{09}$ be the inflationary factor for nominal mpce in 2009-2010. Then the log of the real mpce for each household in the sample in $2009-2010$ is $\log \left(\mathrm{mpce} / \mathrm{P}^{09}\right)=\log (\mathrm{mpce})-\log \left(\mathrm{P}^{09}\right)$. While mpce differs across households, $\mathrm{P}^{09}$ does not and $\log \left(\mathrm{P}^{09}\right)$ will be absorbed into the intercept for the year 2009-2010. Thus, the positive coefficient on the year dummy, y09, measures the inflationary effect on mpce in 2009-2010. 
education increased roughly proportionately with the level of education. The positive effect of education on living standards was the highest among the households with postgraduation as the highest level of education within the family. This was followed by the households with graduation, higher secondary and primary as the highest education. But the poverty-reducing effects of education at any level were reduced significantly and at the highest rate for households with graduation as the highest level of education in 2009-2010. Workers' skill, both in terms of technical education and vocational training, had a significant positive effect on well-being, but there had been no significant change of this effect over time.

The differential effect of non-income criteria on poverty was statistically insignificant. But the differences in prevalence of poverty because of non-income parameters between the households performing farm activities and non-farm activities declined in 2009-2010. The rural dummy is incorporated into the estimating equation to find out the differential effects of non-income parameters on poverty between rural and urban households. This is because structural determinants of poverty are different for rural and urban areas. While the rural economy is mostly agriculture dominated, the majority of the workers in the urban economy are absorbed in the informal manufacturing and tertiary sectors. As the rural dummy has a negative coefficient, the poverty-reducing effect of non-income parameters was lower in the rural areas as compared to urban areas in 2004-2005. There had been no significant change in the rural-urban disparity in the incidence of poverty due to the major non-income factors in India during 2004-2009.

As shown in Table 10.3, the dummy variable for female-headed households has a positive coefficient, implying that they were relatively better off than the maleheaded ones, perhaps because of more job opportunities through the process of feminisation of labour during the post-reforms phase in India. The positive effects of non-income dimensions on the economic well-being of the female-headed households improved further during 2009-2010. Scheduled Tribes and Scheduled Castes among the social groups, and Muslims among the religious groups are mostly deprived in terms of poverty. The level of well-being affected by nonincome criteria was significantly low among the religious minorities compared to Hindus and other religious communities. The economic well-being of this religious group deteriorated further in 2009-2010 as compared to 2004-2005 in India. Both Scheduled Tribes and Scheduled Castes in the country were worse off than the upper caste households, but the latter social group was more badly affected than the former. While the relative deprivation among Scheduled Caste households improved in 2009-2010, it worsened further for the tribal people over time.

The impact of the major non-income dimensions of poverty varied widely across the major states in India mostly because of the differences in structural determinants of poverty, including the growth rates of per capita state GDP and its sectoral components (Das 2009). The governance of the respective state governments in creating infrastructure, attracting private investment and implementing pro-poor measures has also been different. To find out the differential impact of the major non-income parameters across the major states in India, we have estimated a multiple linear regression model as specified in Eq. (10.3) separately for 
each state without incorporating the time-interactive dummy variables. The estimated results are displayed in Table 10.4. ${ }^{8}$ The other observable factors not included in the econometric model have favourable effects on per capita consumption expenditure in every state following the national trend, but at a different scale. Positive and significant coefficients of the time dummy suggest that the level of well-being improved in every state in the country in 2009-2010 as compared to the level in 2004-2005. The negative impact of household size on per capita consumption expenditure was the highest in the southern states of Kerala and Tamil Nadu, and the lowest in Chhattisgarh.

Landownership had no effect on well-being, even in agricultural states like Punjab and West Bengal, while the position of the agricultural households in terms of poverty or well-being was not similar across the states. In Punjab, Haryana and Rajasthan, the households engaged in agricultural activities, both cultivators and agricultural workers taken together, were better off as compared to the non-agricultural households. In West Bengal, on the other hand, along with many other states, the agricultural households were significantly worse off than the non-agricultural households. West Bengal has the largest proportion of land-poor farmers, partly because of historical factors such as the land tenancy system and the land reforms adopted by the government of West Bengal during the late 1970s. Agriculture in the states turns out to be non-profitable probably because of noneconomic land size and other constraints including institutional credit and agricultural marketing. Perhaps, for these reasons, agricultural households were not in better living conditions as compared to those relating to non-farm activities in many states in India. In the rural economy, the households, irrespective of their occupational type, were lagging behind those in urban locations in terms of per capita expenditure everywhere in the country.

The effect of education on the level of well-being was positive and increased with the level of education in every state in India. The poverty-reducing effect of primary education was the highest in Chhattisgarh, followed by West Bengal and Maharashtra. The effect of education at middle school level was also the highest in Chhattisgarh. West Bengal and Tamil Nadu jointly ranked second in terms of the contribution of education at this level to reduce poverty. Kerala led in the poverty reduction effect of education at the graduate and postgraduate levels, followed by West Bengal. This effect was the least in Uttaranchal.

Technical education, a component of workers' skill, improved consumption per capita in all states except Chhattisgarh and Kerala. The contribution of technical education to households' well-being was the highest in Andhra Pradesh and the least in Tamil Nadu. The states exhibiting a higher contribution of technical education include Assam, Odisha and Karnataka.

Attainment of vocational training by the members of the household had mixed effects on poverty. In Andhra Pradesh, Haryana, Uttaranchal and West Bengal, the

${ }^{8}$ As the number of variables is large, we have shown Table 10.4 in two parts. 
Table 10.4 Estimated coefficients of non-income variables by states in India

\begin{tabular}{|c|c|c|c|c|c|c|c|c|c|}
\hline & Intercept & $\begin{array}{l}\text { Household } \\
\text { size }\end{array}$ & $\begin{array}{l}\text { Land } \\
\text { owned }\end{array}$ & $\mathrm{D}^{\mathrm{agr}}$ & $D^{f}$ & $\mathrm{D}^{\text {edu_pri }}$ & $\begin{array}{l}\mathrm{D}_{\text {edu }}^{\text {edu }} \\
\text { middle }\end{array}$ & $\begin{array}{l}\mathrm{D}_{\text {graduate }}^{\text {edu }} \\
\end{array}$ & $D^{\text {edu_pg }}$ \\
\hline Andhra Pradesh & $6.86^{*}$ & $-0.09 *$ & $0.00 *$ & $-0.04 *$ & -0.01 & $0.14 *$ & $0.33^{*}$ & $0.64 *$ & $0.82 *$ \\
\hline Assam & $6.78^{*}$ & $-0.07^{*}$ & $0.00 *$ & $-0.05^{*}$ & $0.06^{*}$ & $0.07 *$ & $0.26^{*}$ & $0.53^{*}$ & $0.74 *$ \\
\hline Bihar & $6.51^{*}$ & $-0.07^{*}$ & $0.00 *$ & 0.00 & 0.00 & $0.11^{*}$ & $0.28 *$ & $0.53^{*}$ & $0.67 *$ \\
\hline Chhattisgarh & $6.43^{*}$ & $-0.04^{*}$ & $0.00 *$ & $-0.04^{*}$ & $0.07 *$ & $0.16^{*}$ & $0.37 *$ & $0.74 *$ & $0.89 *$ \\
\hline Gujarat & $7.01 *$ & $-0.08^{*}$ & $0.00 *$ & $-0.05^{*}$ & $0.04 * *$ & $0.11 *$ & $0.28^{*}$ & $0.62 *$ & $0.79 *$ \\
\hline Haryana & $6.97 *$ & $-0.06^{*}$ & $0.00 *$ & $0.06^{*}$ & $0.05^{*}$ & $0.05^{*}$ & $0.25^{*}$ & $0.59 *$ & $0.84^{*}$ \\
\hline $\begin{array}{l}\text { Himachal } \\
\text { Pradesh }\end{array}$ & $7.17 *$ & $-0.09^{*}$ & $0.00 *$ & -0.02 & $0.08 *$ & $0.05 *$ & $0.25^{*}$ & $0.52 *$ & $0.75^{*}$ \\
\hline Jharkhand & $6.66^{*}$ & $-0.07^{*}$ & $0.00 *$ & $-0.03^{*}$ & $0.07 *$ & $0.09 *$ & $0.25^{*}$ & $0.57 *$ & $0.86^{*}$ \\
\hline Karnataka & $6.71^{*}$ & $-0.06^{*}$ & $0.00 *$ & 0.01 & $0.05 *$ & $0.12 *$ & $0.34 *$ & $0.69 *$ & $0.91 *$ \\
\hline Kerala & $7.04 *$ & $-0.11 *$ & $0.00 *$ & $-0.03 * *$ & 0.01 & $0.12 *$ & $0.33^{*}$ & $0.77 *$ & $1.03^{*}$ \\
\hline Madhya Pradesh & $6.59 *$ & $-0.06^{*}$ & $0.00 *$ & 0.01 & $0.07 *$ & $0.09 *$ & $0.23 *$ & $0.60 *$ & $0.74 *$ \\
\hline Maharashtra & $6.94 *$ & $-0.07^{*}$ & $0.00 *$ & $-0.08^{*}$ & $0.05^{*}$ & $0.13 *$ & $0.30 *$ & $0.70 *$ & $0.88^{*}$ \\
\hline Odisha & $6.44 *$ & $-0.06^{*}$ & $0.00 *$ & $-0.09 *$ & $0.08 *$ & $0.12 *$ & $0.33^{*}$ & $0.61 *$ & $0.81 *$ \\
\hline Punjab & $7.04 *$ & $-0.06^{*}$ & $0.00 *$ & $0.04 *$ & $0.09 *$ & $0.08 *$ & $0.27 *$ & $0.62 *$ & $0.83^{*}$ \\
\hline Rajasthan & $6.88^{*}$ & $-0.06^{*}$ & $0.00 *$ & $0.04 *$ & $0.07 *$ & $0.10^{*}$ & $0.21 *$ & $0.53 *$ & $0.67 *$ \\
\hline Tamil Nadu & $6.88 *$ & $-0.11 *$ & $0.00 *$ & $-0.07 *$ & $-0.03 *$ & $0.11^{*}$ & $0.36^{*}$ & $0.73^{*}$ & 0.94* \\
\hline Uttar Pradesh & $6.63^{*}$ & $-0.06^{*}$ & $0.00 *$ & $0.01 * *$ & $0.02 * *$ & $0.08 *$ & $0.23^{*}$ & $0.55^{*}$ & $0.67 *$ \\
\hline Uttaranchal & $6.90 *$ & $-0.07 *$ & $0.00 *$ & $-0.06^{*}$ & $0.11 *$ & $0.06^{*}$ & $0.16^{*}$ & $0.44 *$ & $0.56^{*}$ \\
\hline West Bengal & $6.79 *$ & $-0.07^{*}$ & $0.00 *$ & $-0.08^{*}$ & $0.05^{*}$ & $0.13^{*}$ & $0.36^{*}$ & $0.76^{*}$ & $1.02 *$ \\
\hline
\end{tabular}

\begin{tabular}{l|l|l|l|l|l|l|l}
\hline & $\mathrm{D}^{\text {edu_tech }}$ & $\mathrm{D}^{\text {training }}$ & $\mathrm{D}^{\text {muslim }}$ & $\mathrm{D}^{\text {st }}$ & $\mathrm{D}^{\mathrm{sc}}$ & $\mathrm{D}^{\mathrm{yr}}$ & $\mathrm{D}^{\mathrm{r}}$ \\
\hline Andhra Pradesh & $0.20^{*}$ & $-0.09^{*}$ & $-0.06^{*}$ & $-0.29^{*}$ & $-0.11^{*}$ & $0.57^{*}$ & $-0.25^{*}$ \\
\hline Assam & $0.19^{*}$ & $0.08^{*}$ & $-0.11^{*}$ & $-0.09^{*}$ & $-0.12^{*}$ & $0.38^{*}$ & $-0.25^{*}$ \\
\hline Bihar & $0.12^{*}$ & 0.00 & -0.01 & $-0.12^{*}$ & $-0.13^{*}$ & $0.45^{*}$ & $-0.17^{*}$ \\
\hline Chhattisgarh & -0.05 & 0.08 & 0.07 & $-0.18^{*}$ & $-0.04^{*}$ & $0.38^{*}$ & $-0.25^{*}$ \\
\hline Gujarat & $0.11^{*}$ & -0.04 & $-0.09^{*}$ & $-0.16^{*}$ & $-0.16^{*}$ & $0.45^{*}$ & $-0.30^{*}$ \\
\hline Haryana & $0.16^{*}$ & $-0.10^{*}$ & $-0.24^{*}$ & -0.05 & $-0.27^{*}$ & $0.55^{*}$ & $-0.16^{*}$ \\
\hline Himachal Pradesh & $0.12^{*}$ & 0.03 & -0.01 & -0.02 & $-0.11^{*}$ & $0.46^{*}$ & $-0.26^{*}$ \\
\hline Jharkhand & $0.12^{*}$ & 0.00 & $-0.07^{*}$ & $-0.15^{*}$ & $-0.13^{*}$ & $0.41^{*}$ & $-0.26^{*}$ \\
\hline Karnataka & $0.17^{*}$ & $0.14^{*}$ & $-0.12^{*}$ & $-0.12^{*}$ & $-0.17^{*}$ & $0.46^{*}$ & $-0.26^{*}$ \\
\hline Kerala & 0.00 & -0.04 & $0.07^{*}$ & $-0.38^{*}$ & $-0.21^{*}$ & $0.49^{*}$ & $-0.03^{*}$ \\
\hline Madhya Pradesh & $0.13^{*}$ & $0.10^{*}$ & -0.02 & $-0.20^{*}$ & $-0.15^{*}$ & $0.44^{*}$ & $-0.24^{*}$ \\
\hline Maharashtra & $0.09^{*}$ & -0.02 & $-0.15^{*}$ & $-0.20^{*}$ & $-0.20^{*}$ & $0.50^{*}$ & $-0.38^{*}$ \\
\hline Odisha & $0.19^{*}$ & -0.03 & $-0.07^{* *}$ & $-0.32^{*}$ & $-0.12^{*}$ & $0.51^{*}$ & $-0.24^{*}$ \\
\hline Punjab & $0.07^{*}$ & -0.05 & $-0.13^{*}$ & $-0.16^{*}$ & $-0.31^{*}$ & $0.52^{*}$ & $-0.09^{*}$ \\
\hline Rajasthan & $0.13^{*}$ & 0.00 & $-0.07^{*}$ & $-0.18^{*}$ & $-0.17^{*}$ & $0.51^{*}$ & $-0.24^{*}$ \\
\hline Tamil Nadu & $0.05^{*}$ & 0.01 & $0.11^{*}$ & $-0.16^{*}$ & $-0.12^{*}$ & $0.44^{*}$ & $-0.25^{*}$ \\
\hline Uttar Pradesh & $0.12^{*}$ & -0.02 & $-0.02^{*}$ & $-0.14^{*}$ & $-0.14^{*}$ & $0.44^{*}$ & $-0.18^{*}$ \\
\hline Uttaranchal & $0.11^{*}$ & $-0.11^{*}$ & $-0.06^{*}$ & 0.01 & $-0.17^{*}$ & $0.48^{*}$ & $-0.26^{*}$ \\
\hline West Bengal & $0.13^{*}$ & $-0.04^{*}$ & $-0.10^{*}$ & $-0.12^{*}$ & $-0.13^{*}$ & $0.39^{*}$ & $-0.27^{*}$ \\
\hline
\end{tabular}

Note $*$ Significant at $1 \%$ level

**Significant at $5 \%$ level

*** Significant at $10 \%$ level

Source As for Table 10.1 
effect was negative, while in Assam, Karnataka and Madhya Pradesh, the effect was positive. In the majority of the states in India, the effect was insignificant.

The effects of non-income parameters on poverty were higher for femaleheaded households than for the male-headed ones in most of the states, but at different scales. In Uttaranchal, the effect was the highest, followed by Punjab, and it was the lowest in Uttar Pradesh. In a few states like Bihar, Andhra Pradesh and Kerala, there had been no significant difference in the impact of those factors by gender. In Tamil Nadu, on the other hand, the poverty-reducing effect of gender was significantly less.

The poverty-reducing effect of the non-income parameters like land and education was significantly less for the Muslims as compared to Hindus and other religious groups in almost every state in India, though unevenly. The gap between Muslims and other religions was the highest in Haryana, in terms of the impact of these factors on poverty. The gap was the least in Uttar Pradesh. In Tamil Nadu, on the other hand, the effect of non-income variables was more for Muslims than other religious groups. Traditionally, Scheduled Tribes have been more deprived among the different social groups in India. However, in some states, the poverty-reducing effect was low among Scheduled Castes as compared to the tribal people. The difference in the effect on poverty among Dalits was the highest in Kerala and the least in Assam. In some states like Haryana, Himachal Pradesh, and Uttaranchal, however, the gap was not statistically significant. The gap in the poverty-reducing effect for Scheduled Caste households as compared to the households in other social groups was the highest in Haryana and the lowest in Chhattisgarh.

\subsection{Conclusions}

There is no doubt that GDP growth has improved during the post-reforms period in India, but attempts to quantify change in poverty levels have not led to a general agreement on the magnitude of poverty reduction during this period. In this study, we have mostly used the notion of relative poverty to look into the effects of nonincome dimensions on the incidence of poverty. The macroeconomics of poverty can be looked at mainly through the growth and distribution effects. An increase in mean income would reduce poverty, provided that the distribution factor was insignificant. When mean income growth is accompanied by more unequal income distribution, the poverty effect depends on which of the two effects dominate. If mean income grows with a drop in inequality, both growth and distribution factors are favourable to the poor and poverty reduces at a faster pace.

This study concentrates mainly on relative poverty, which can be estimated by taking the distribution of income or consumption into account. The incidence, depth and severity of poverty and the effects of the major non-income dimensions on poverty have been examined after more than one decade of the initiation of the process of integration in India by using household-level unit data provided by 
the NSSO. Incidence of poverty has been looked at by using the relative poverty line at different thresholds, namely 75 and $50 \%$ of the median of the distribution of per capita expenditure of the respective population groups. The poverty line at $50 \%$ of the median of the expenditure distribution is used in estimating chronic poverty. The paper focuses mainly on education, type of employment, land rights, social and religious factors, and gender-related issues among the non-income dimensions of poverty. Estimation of the contributions of non-income parameters to poverty is based on an independently pooled cross section constructed from randomly selected sample households as recorded in the NSS 61st and 66th rounds survey in India.

The evidence discussed in this paper suggests an increase in urban-rural disparity in terms of prevalence, depth and severity of poverty during the post-liberalisation period. While the relative poverty within rural areas remained roughly at the same level, in urban areas, it increased noticeably during this period. The ruralurban gap in relative deprivation varied widely across the major states in India. The rising poverty incidence on the basis of relative poverty line in urban areas supports the hypothesis that urban inequality has increased significantly during the post-reforms period in India.

The effects of non-income parameters on poverty improved in 2009-2010 as compared to the effects in 2004-2005. Land as a productive asset had very little positive effect on well-being. Landownership had no effect on well-being even in agricultural states like Punjab and West Bengal. The poverty-reducing effect of non-income parameters was lower in the rural areas as compared to urban areas, and there was no significant improvement over time. The households with education at any level were better off compared to others, and the poverty-reducing effect of education increased roughly proportionately with the level of education. The level of skill, both in terms of technical education and vocational training, had a significant positive effect on well-being, but there was no significant change of this effect over time. Scheduled Tribes and Scheduled Castes among the social groups, and Muslims among religious groups are mostly deprived in terms of poverty.

Some states have made substantial progress in poverty reduction, while others have not performed well, causing significant regional differences in the concentration of poor people. The incidence of poverty has also been unevenly distributed across locations within a state and among different groups of people. Poverty, particularly chronic poverty, has traditionally been concentrated mainly in dry land regions characterised by frequent failure of crops and in hilly regions with limited access to means of living. Dalits and religious minorities have been deprived socially and economically because of historical discrimination. In this context, the role of subnational governments assumes significance because the state governments have a major responsibility for agricultural development and provision of services in social sectors like health and education. 
Open Access This chapter is distributed under the terms of the Creative Commons Attribution Noncommercial License, which permits any noncommercial use, distribution, and reproduction in any medium, provided the original author(s) and source are credited.

\section{References}

Chen S, Ravallion M (2004) How have the world's poorest fared since the early 1980s? World Bank Policy Research Department Working Paper 3341, World Bank; Washington, DC

Das P (2009) Economic growth, poverty and inequality: Indian experience of reforms and development. Paper presented in the inaugural conference of courant research center poverty, equity, and growth in developing and transition countries: statistical methods, empirical analyses, and policy issues, University of Göttingen, Germany, 1-3 July 2009

Das P (2010) The impact of trade openness on poverty and inequality: dynamic panel analysis with Indian data, Int J Arts Sci 3(13):427-438 (2010), CD-ROM ISSN: 1994-6934, InternationalJournal.org

Das P (2012) Relative deprivation among religious and social groups in India: measuring prevalence, depth and severity of poverty with NSS unit Data. J income wealth 34(1):47-56

Government of India (2012) Poverty estimates for 2009-2010. Press Information Bureau, Planning Commission, India

Krishnaji N (2012) Abolish the poverty line. Econ Polit Wkly 47(15):10-11

Radhakrishna R, Panda M (2006) Macroeconomics of poverty reduction: India case study, a study carried out for the Asia-Pacific Regional Programme on the macroeconomics of poverty reduction, United Nations Development Programme, Indira Gandhi Institute of Development Research, Mumbai

Sanyal MK, Das P (2008) Chronic poverty, inequality and non-income dimensions of development in India: 1980-1981 to 2006-2007. Paper presented in the international conference on eradicating chronic poverty in India: policy issues and challenges, organized by chronic poverty research centre, India and centre for the study of social systems, school of social sciences, Jawaharlal Nehru University, New Delhi, on 1st-3rd Oct 2008

Wooldridge JM (2009) Econometrics, Indian edn. Cengage Learning India Private Limited, New Delhi 